\title{
12
}

\section{OS PROCESSOS DE INSTITUCIONALIZAÇÃO DA PEDAGOGIA HISTÓRICO-CRÍTICA*}

Viviane Grzechota Selzler

Paulino José Orso

\section{Introdução}

A institucionalização da Pedagogia Histórico-Crítica na escola pública contemporânea, inserida numa sociedade de classes, tem sido um grande desafio, pois, trata-se da adoção por um estado ou município, de uma proposta contra hegemônica ${ }^{1}$, que, como afirma Saviani, propõe-se a "[...] produzir, direta e intencionalmente, em cada indivíduo singular, a humanidade que é produzida histórica e coletivamente pelo conjunto dos homens." (SAVIANI, 2013a, p. 13). E, como tal, após mais de 40 anos de sua gênese, segue seu percurso de resistência e luta pela construção e implementação de uma educação emancipadora.

A pedagogia histórico-crítica, surge no debate educacional brasileiro na década de 1980, tendo seus primeiros escritos em 1979, em meio à ditadura civil-militar. Nesse período, o país estava passando por grandes mudanças sociais, políticas, econômicas, educacionais e culturais, na tentativa de "se modernizar" e acompanhar os países mais desenvolvidos.

Para elaborar a PHC, Dermeval Saviani fez um estudo minucioso das concepções pedagógicas existentes e, ao verificar que se caracterizavam basicamente por serem não-críticas e crítico-reprodutivistas, propôs uma nova concepção de educação, voltada para a emancipação humana - a Pedagogia Histórico-Crítica - comprometida com a apropriação do

\footnotetext{
*DOI - 10.29388/978-65-86678-91-8-0-f.253-272

${ }^{1}$ Compreende-se como Pedagogias contra hegemônica as orientações teóricas não dominantes que dispõem intencional e sistematicamente a educação a serviço das forças que lutam para transformar a ordem vigente buscando instaurar uma nova sociedade.
} 
conhecimento científico e a socialização da cultura mais elaborada produzida coletivamente pela humanidade.

A partir da década de 1990, ela começou a figurar nos documentos oficiais do Estado do Paraná e em diversas redes municipais de educação. No intuito de identificar se a PHC pressupõe uma forma única ou diversa de se institucionalizar nas diferentes redes educacionais, neste artigo, fizemos uma análise de quatro das que consideramos as principais experiências de institucionalização, a saber, dos municípios de Itaipulândia, Cascavel, Bauru e Limeira. Com isso, também analisamos suas principais características e verificamos até que ponto seus processos se aproximam ou divergem.

Para nortear a discussão, orientamo-nos pela seguinte questão: $A$ partir das experiências de institucionalização da PHC existentes é possível depreender se há um caminho ou uma forma única de fazê-la ou cada local deve fazê-la de uma forma específica, conforme as condições e possibilidades permitem?

\section{Pedagogia histórica-crítica: desenvolvimento e contribuições}

A pedagogia histórico-crítica é considerada um marco na educação brasileira por se tratar de uma teoria pedagógica explicitamente comprometida com a classe trabalhadora. Diferente das demais, tem o foco na transmissão de conteúdos científicos, artísticos e filosóficos voltados para o desenvolvimento de todas as dimensões humanas.

Forjada em meio ao obscurantismo do regime civil-militar, a PHC se constitui numa teoria pedagógica comprometida com a transformação social, com a superação do modo de produção capitalista e com a emancipação humana. Noutras palavras, "o que a pedagogia históricocrítica se propõe é articular a educação escolar com a luta da classe trabalhadora pela superação do capitalismo e implantação do socialismo" (SAVIANI, 2012, p. 31).

Seu principal precursor, o professor Demerval Saviani, em sua tese de doutorado defendida em 1971, que resultou na elaboração da obra Educação Brasileira: estrutura e sistema, publicada em livro em 1973, observou o sistema educacional brasileiro e percebeu a ausência de um sistema educacional que garantisse à população uma educação de qualidade. Diante disso, iniciou os estudos na tentativa de construir uma teoria pedagógica voltada para os interesses da classe trabalhadora, que 
culminou nos capítulos da obra Escola e Democracia, que marca o início de uma teoria pedagógica revolucionária, a pedagogia histórico-crítica.

Desde os primeiros escritos acerca dessa teoria, 0 autor demonstrava o interesse em elaborar uma proposta educacional que superasse as teorias não-críticas e as crítico-reprodutivistas e compreendesse a educação a partir de seu desenvolvimento históricoobjetivo (SAVIANI, 2013a, p. 80). Entendia que, mesmo sendo determinada, a educação também poderia se transformar num meio de determinação social e, portanto, de mudança da prática social.

Assim, com o fim da ditadura, imbuídos deste espírito, muitos profissionais da educação se somam a Saviani na luta pela construção coletiva de uma nova teoria pedagógica. Em 1986, é criado o grupo de estudos e pesquisas HISTEDBR, por meio do qual, a PHC começa a se expandir por diversos estados e municípios do país.

Após isso, em 1990, ela adquire um novo status a partir de sua institucionalização pelo estado do Paraná, que, por meio do Currículo Básico para a Rede Pública do Paraná, a transformou na proposta pedagógica oficial para toda a rede estadual de educação. Em sua esteira, diversos municípios brasileiros também tentaram fazer o mesmo, adotaram-na como referência teórico-metodológica para toda sua rede educacional.

No atual momento, passados mais de 40 anos de suas primeiras elaborações, com um acúmulo bastante grande de produções, reflexões e experiências práticas, isto é, de processos de institucionalização, nos propomos a verificar até que ponto eles coincidem ou divergem em suas formas. Desse modo, nos voltamos para o passado e verificamos suas formas de desenvolvimento para poder avançar, procurando superar os problemas e entraves já evidenciados.

\section{Institucionalização da pedagogia histórico-crítica em quatro redes municipais de educação}

A Pedagogia Histórico-Crítica entende o espaço escolar como local precípuo para socialização do saber sistematizado, produzido e acumulado historicamente pela humanidade. Nesse sentido, a sua institucionalização pelas redes municipais e estaduais de educação se torna um meio de viabilizar essa proposta pedagógica para que seja assumida pelo conjunto dos profissionais da educação e estendida a todos os alunos de igual modo, pos- 
sibilitando a construção de uma nova educação e, por extensão, de uma nova sociedade.

O processo de institucionalização da $\mathrm{PHC}$, como vimos, iniciou-se na última década do século passado, nos anos de 1990, no estado do Paraná. Depois, diversos municípios deste estado e outros para além dele, também tentaram fazer o mesmo, adotando a pedagogia histórico-crítica como sua pedagogia oficial.

Em geral, a institucionalização da PHC ocorre como resultado de um duplo movimento. Um deles, decorre de grupos de educadores que se mobilizam e organizam para exigir dos governos a implementação de uma proposta pedagógica diferente das existentes, que contemple os princípios de uma concepção progressista de educação e sociedade. O outro, é oriundo de iniciativas oficiais, quando os próprios governantes e suas equipes pedagógicas, resolvem adotar a PHC como sua proposta pedagógica oficial.

As experiências investigadas, porém, demonstram que, em cada local, guardadas pequenas semelhanças, as formas de institucionalização têm assumido características próprias, decorrentes dos diferentes elementos que configuram cada um dos espaços políticos, sociais e educacionais. Contudo, para melhor compreender as semelhanças e diferenças de cada uma das experiências analisadas, vejamos as especificidades de cada um dos municípios mencionados anteriormente.

No caso de Itaipulândia, por um longo período, a Secretaria de Educação, Cultura e Esportes do município, seguiu as orientações da Associação Educacional do Oeste do Paraná - ASSOESTE - e, após seu desmantelamento, com a constituição do Departamento de Educação da AMOP (Associação dos Municípios do Oeste do Paraná), passou a se orientar por ele. Desde então, vinha perseguindo uma concepção de educação crítica e transformadora.

Com esse intuito, de acordo com Balzan (2014), já nos primeiros anos após a emancipação do município (1992), foi elaborado um documento norteador para a educação municipal, fundamentado no Currículo Básico para a Escola Pública do Paraná, compreendido como um currículo embasado na pedagogia histórico-crítica.

Porém, no final da década de 1990, por orientação do Ministério da Educação, passou-se a seguir os PCNs (Parâmetros Curriculares Nacionais). Posteriormente, no início do ano de 2000, são retomadas as discussões em torno da PHC, e, em 2004, os professores decidiram em assembleia, adotar 
a pedagogia histórico-crítica como referencial teórico para toda a rede municipal de educação.

De acordo com uma das professoras entrevistadas ${ }^{2}$,

Dentre os fatores que levaram à definição pela $\mathrm{PHC}$ como perspectiva direcionadora do trabalho pedagógico no município, destacamos: o ecletismo pedagógico presente nas orientações oficiais e na prática pedagógica na rede municipal, pouca aprendizagem dos alunos, falta de clareza teórica e ausência de uma proposta clara que orientasse o trabalho pedagógico em uma única direção. Dentre as pedagogias estudadas, definiu-se, naquele momento, pela PHC, por estar mais em consonância com as necessidades e objetivos defendidos pelo grupo de professores (RELATO DA PROFESSORA B).

Segundo Balzan (2014, p. 109), que fez sua dissertação de mestrado sobre a institucionalização da PHC no município, o processo foi antecedido por um longo período de formação, estudos, leituras e sistematizações sobre a teoria e prática pedagógica, seja por meio do Departamento de Educação da AMOP, da Secretaria Municipal de Educação ou de palestras formativas sobre temáticas específicas, no que se refere aos fundamentos filosóficos, pedagógicos, psicológicos e didáticos da pedagogia históricocrítica.

Para dirimir dúvidas e compreender os pressupostos da nova teoria pedagógica, foram organizados grupos de estudos com assessoramento direto de professores do curso de pedagogia da Universidade Estadual do Oeste do Paraná - Campus de Cascavel e, de modo especial, com o professor João Luiz Gasparin, da Universidade Estadual de Maringá (BALZAN, 2014, p. 110).

Na sequência, diante das dificuldades encontradas, especialmente às relacionadas aos materiais didáticos e paradidáticos, aos conteúdos curriculares, que atendessem à perspectiva da PHC, tomando como referência o Currículo básico para a Escola Pública Municipal: Educação infantil e ensino fundamental (2007) (BALZAN, 2014 p. 112), um grupo de professores defendeu a necessidade de elaboração de material didático próprio para auxiliar os docentes em sua prática pedagógica.

Apesar de não haver nenhum "modelo" para seguir, exceto o Currículo Básico para a Rede Pública do Paraná, havia bastante clareza, ao

\footnotetext{
${ }^{2}$ Para manter o anonimato dos professores entrevistados, serão identificados por RELATOS DA PROFESSORA A, RELATOS DA PROFESSORA B, RELATOS DO PROFESSOR C, etc.
} 
menos por parte de um grupo de docentes, quanto ao percurso a trilhar para se institucionalizar a $\mathrm{PHC}$ na rede municipal.

De acordo com a PROFESSORA A,

Desde seu início, os docentes tinham clareza de que a institucionalização da PHC se tratava de um processo a ser apropriado na e pela instituição. Mas, não se tinha noção de que seria um processo tão longo, desafiador, árduo, exaustivo e com retrocessos, apesar dos avanços (RELATO DA PROFESSORA A).

Contudo, a despeito dos percalços, a elaboração de uma "política educacional" municipal passou a se constituir em uma meta e em um dos principais desafios, pois visava promover uma relativa estabilidade à prática pedagógica desenvolvida pelos professores em sala de aula.

Segundo Balzan (2014), concomitante à institucionalização da PHC, também foi necessário elaborar, sistematizar e propor ao poder público a melhoria das condições de trabalho no intuito de viabilizar o ensino e aprendizagem de acordo com a nova perspectiva pedagógica. Dentre elas, destacamos:

a) Alteração do regime de trabalho: ampliação da jornada de trabalho de 20 para 40 horas semanais;

b) Alteração da jornada de trabalho: o professor tem uma jornada de 40 horas semanais atuando em única turma - 20 horas em sala com o ensino, 12 horas atividades e 08 horas destinadas ao complemento de estudos para os alunos;

c) Ampliação da jornada escolar: tempo de ensino aos alunos compreende 960 horas anuais;

d) Implantação progressiva da educação integral numa perspectiva de valorização do ensino, em detrimento a projetos culturais, esportivos e recreativos;

e) Formação e valorização dos professores: Instituição do Programa de Desenvolvimento Educacional de Itaipulândia - PDE Municipal, vinculado à ascensão na carreira;

f) Produção coletiva de material de apoio ao ensino, para os alunos;

g) Realização de um concurso público para o magistério e outras funções (BALZAN, 2014, p. 117).

A institucionalização da PHC, portanto, desencadeou um processo de lutas em torno de um conjunto de políticas públicas que, por um lado, 
garantiram a melhoria das condições de trabalho e, por outro, a melhoria na qualidade de ensino, atendendo alguns dos requisitos básicos defendidos pela pedagogia histórico-crítica.

Diante do exposto, verifica-se uma série de ações realizadas, relacionadas à organização dos professores, ao estudo, à formação, ao planejamento, ao currículo, ao tempo, ao espaço escolar, ao regime e jornada de trabalho dos professores, ao plano de carreira, à valorização profissional, à produção coletiva de material, entre outras, com vistas a institucionalização da PHC.

No caso de Cascavel, a institucionalização da PHC, aconteceu de modo diferente. As primeiras iniciativas em torno desse processo ocorreram ainda em 2004, no contexto das discussões iniciadas pela Secretaria Estadual de Educação para redefinir os parâmetros curriculares e, posteriormente, em 2005, quando o Departamento de Educação da AMOP, que congregava 50 municípios à época, em conjunto com os secretários municipais de educação, começa a discutir sobre a necessidade de se construir os referenciais curriculares para todos os municípios vinculados à Associação.

Em 2006, iniciaram-se os trabalhos junto à essa Associação, para construção coletiva do Currículo Básico para a Escola Pública Municipal, que foi publicado em 2007, inclusive, com a participação do próprio secretário municipal de educação de Cascavel. Todavia, no meio do processo, ele se retira desse coletivo, e o município inicia a construção de um currículo próprio, centrado na pedagogia histórico-crítica. Diga-se de passagem, que, apesar do Currículo da AMOP ter como referência o Currículo Básico do Paraná e conter todos os pressupostos defendidos pela PHC, em momento algum fez uma defesa ou uma opção explícita da ou pela PHC.

Desse modo, segundo a professora D, o currículo de Cascavel adquiriu características próprias e se configurou como um documento fundamentado na PHC, quando o grupo que coordenou os trabalhos de sua elaboração, procurou orientações e referências com profissionais que atuam no ensino superior, dentre eles, o professor Newton Duarte, da UNESP, campus de Araraquara-SP, que estava ligado à psicologia históricocultural e à pedagogia histórico-crítica.

Uma das grandes questões e um grande salto que o município de Cascavel deu naquele momento foi conseguir o professor Newton Duarte como um assessor geral. Foi ele quem nos indicou textos, au- 
tores e questões que nós precisávamos reler e buscar em textos originais. Nós tínhamos muito equívocos de compreensões em relação ao método tanto em Marx, como em Vigotski. E a própria mistura do campo do multiculturalismo com a questão PHC, que foi o professor Newton Duarte que foi nos clareando e nos inserindo numa leitura mais, naquele momento, limpa e clara sobre aquelas questões. Temos muito até hoje para avançar. Mas naquele momento foi um grande salto. E foi daí que saiu essa linha mais clara em relação a PHC (RELATO DO PROFESSOR D).

Nesse caso, a institucionalização do currículo ocorreu em 2008, após um longo processo de trabalho e discussão coletiva, articulando a assessoria geral, a equipe pedagógica da secretaria municipal de educação e um significativo grupo de professores da rede.

Todavia, para institucionalizar a PHC, não bastava construir um currículo. Havia a necessidade de formação permanente. Para isso, demandava

Elaborar um projeto de formação continuada para rede, convidando profissionais que realmente tem embasamento teórico na Pedagogia Histórico-Crítica ou na psicologia histórico-cultural, que consigam fazer um projeto realmente coletivo profundo, bem articulado para todos os professores da rede (RELATO DA PROFESSORA D).

Desse modo, após a sua publicação, ao menos durante a gestão em que foi elaborado, também se instituiu um intenso processo de formação junto aos docentes da rede, pois, entendia-se que, sem ela, seria praticamente impossível implementar o currículo, uma vez que se tratava de uma proposta nova, pouco conhecida pelos docentes, e que, além do mais, posicionava-se na contramão das propostas hegemônicas no momento.

Portanto, havia a necessidade de zelar tanto pela formação inicial, como continuada dos docentes. Mas, como a inicial escapava do seu controle, a recurso era desencadear um sólido processo de formação continuada no intuito de superar limitações decorrentes da formação inicial.

Não basta você dizer: eu trabalho com a Pedagogia Histórico-Crítica. Você tem que ter domínio da dos pressupostos filosóficos, sociológi- 
cos e psicológicos. Tem que ter domínio dos conteúdos da disciplina. Tem que ter o compromisso social, no sentido de aprofundar a formação específicas das disciplinas, dos conteúdos das disciplinas escolares, e da formação política, pois isso está presente na forma que você irá abordar o conteúdo (RELATO DA PROFESSORA D).

De acordo com o relato da professora, de um lado, havia a necessidade de formação continuada para possibilitar a apropriação teórica da PHC e, por outro, reduzir a carga horária e melhorar as condições de trabalho e a infraestrutura das escolas.

Quanto à forma de se institucionalizar a PHC nas redes municipais, a referida professora, fala que não há uma fórmula que possa ser aplicada em todos os locais. Para ela, depende de vários fatores, dentre os quais, do grupo que está à frente da educação em cada município, do envolvimento dos professores que possuem liderança nas escolas, no Sindicato e nos partidos políticos, da história e das condições de cada lugar, assim como dos recursos financeiros disponíveis para investir na formação continuada e na melhoria na carreira (RELATO DA PROFESSORA D).

Todavia, defende a priorização da formação, seja por meio de profissionais especializados ou através de leituras e discussões em grupos de estudos, condição para que haja compreensão e domínio de todos os aspectos que compõe a Pedagogia Histórico-Crítica, para que "realmente se possa encaminhar o trabalho de escrita de um currículo e sua institucionalização", considerando tanto seus pressupostos teóricos como a concepção de mundo, de homem, de educação, de escola pública, que caracterizam e distinguem a PHC.

Por sua vez, o processo de implantação da PHC em Bauru, no estado de São Paulo, teve como objetivo principal a elaboração de dois documentos para nortear o ensino no município: a Proposta Curricular para a Educação Infantil e o Currículo Comum para o Ensino Fundamental. Esses documentos foram construídos tendo como referências a psicologia histórico-cultural, no que diz respeito à defesa da educação como propulsora do desenvolvimento humano, e da pedagogia histórico-crítica, no que tange à função da escola como ambiente destinado à socialização do conhecimento.

De acordo com a professora $\mathrm{E}$, a implantação ocorreu no período de 2011 a 2016, por meio de um projeto de extensão da Universidade Estadual Paulista (UNESP) - Campus de Araraquara-SP, atendendo a um convite da 
Secretaria de Educação para construir uma proposta pedagógica para a Educação Infantil do município. Contudo, a princípio não havia um projeto específico pensado em relação à $\mathrm{PHC}$.

Então no momento em que o convite ocorre para o trabalho de construção da proposta pedagógica para a educação infantil ele não vem tanto motivado pelo propósito de institucionalizar a pedagogia histórico-crítica, mas para construir uma proposta de fundamentação histórico cultural para a educação infantil (RELATO DA PROFESSORA E).

Assim, como o projeto havia sido demandado a uma docente que estava vinculada à psicologia histórico-cultural, tanto a Proposta Curricular para a Educação Infantil como o Currículo Comum para o Ensino Fundamental, adquiriram uma conotação maior da psicologia históricocultural. Portanto, não dá para se afirmar que se tratou propriamente da institucionalização da pedagogia histórico-crítica.

No entanto, como havia necessidade de elaboração de um currículo para a Educação Infantil, com o desenvolvimento dos trabalhos, também foram sendo incorporados os pressupostos propriamente pedagógicos.

[...] é claro que no processo a gente vai incorporando, a gente traz a pedagogia histórico-crítica e aparece no texto da própria proposta, mas no próprio currículo transparece um pouco a característica que estou relatando aqui: dessa ênfase numa busca da psicologia histórico cultural de desenvolvimento e a PHC, num primeiro momento como fundo e não como figura, gradativamente sendo incorporada, mas não tendo esse protagonismo no processo. (RELATO DA PROFESSORA E).

Por conta disso, relata a entrevistada, "eu digo que embora o currículo tenha uma vinculação com a PHC, não sei se daria para chamar esse processo todo no município de Bauru como institucionalização da pedagogia histórico-crítica" (idem).

Vê-se, pois, que, inicialmente, o processo ocorreu a partir de um convite por parte da divisão de educação infantil, para pensar num novo currículo para esta etapa de escolarização, ficando circunscrito à Educação Infantil. Em seguida, também se desenvolveu um trabalho destinado aos 
anos iniciais do Ensino Fundamental, mas não abarcou toda rede municipal de educação.

A partir desse trabalho, posteriormente também ocorreu um trabaIho no ensino fundamental, mas ele não foi um processo orgânico e unitário. Mas processos independentes. Então foi mais um movimento da educação infantil no município, no esforço de construir uma identidade própria, de renovar algumas formas de pensar a educação infantil (RELATO DA PROFESSORA E).

Segundo Kamazaki (2018), em 2016, também foi elaborado o Currículo Comum do Ensino Fundamental, que seguiu a mesma perspectiva. No entanto, as discussões iniciais começaram ainda no ano 2000 (KAMAZAKI, 2018, p. 173).

Esse documento também foi elaborado sob a orientação do Departamento de Educação e Psicologia da UNESP. Segundo a autora, uma versão preliminar foi concluída em 2013, com a participação ativa da Secretaria Municipal de Educação e dos professores. Todavia, a aplicação em sala de aula e os estudos realizados indicaram a necessidade de reorganizá-lo, para corrigir falhas, decorrentes da não compreensão da perspectiva teórica adotada.

A versão final do documento resultou de um processo de revisão, iniciado em 2015, por meio de grupos de trabalho, por área de conhecimento, sobre os principais teóricos na área da psicologia históricocultural e da pedagogia histórico-crítica, com o objetivo de instrumentalizar os professores e garantir uma "visão integral do currículo e a articulação entre os princípios teóricos e a escolha curricular de cada área" (KAMAZAKI, 2018, p. 173).

Diferente disso, em relação à elaboração do currículo para a Educação Infantil, o trabalho realizado ficou restrito a um grupo de profissionais, uma pequena equipe. Assim, não ocorreu a apropriação coletiva dos fundamentos teóricos e dos encaminhamentos metodológicos por parte do conjunto de professores, prejudicando o trabalho nas escolas.

Em decorrência disso, como o trabalho de elaboração curricular envolveu apenas um pequeno grupo, o principal desafio foi alcançar um grande contingente de pessoas que trabalhavam na rede, envolvê-los no processo, favorecendo a participação e a construção coletiva. 
Contudo, o processo adotado acarretou uma série de problemas.

É você elaborar um currículo e apresentar para as pessoas e dizer: agora é assim que se trabalha nessa Rede. [...] como é que você faz um processo participativo com 9 mil professores né, nas redes grandes? Como é que você faz isso? Geralmente com equipes pequenas tocando trabalho. [...] Como é que se alcança todos esses professores no processo de construção? $O$ que a gente fez foi a tentativa para trabalhar com as diretoras. Trabalhar com 64 diretoras é possível. Fazer as reuniões com 32 de manhã e 32 à tarde. A forma que chegou em todas as escolas ficava na dependência de a diretora levar e trazer né, as questões da equipe (RELATO DA PROFESSORA E).

Segundo a educadora, garantir a participação nos processos de construção é um desafio para institucionalizar a PHC nas redes dos estados e municípios e essa é uma dificuldade, pois, decorre dos limites para se promover a organização, a participação coletiva e o envolvimento significativo num trabalho pedagógico com todos os profissionais da educação. Geralmente, o trabalho de elaboração fica circunscrito a uma equipe pequena, e depois, apresenta-se aos demais como algo que deve ser executado.

Por fim, no caso de Limeira-SP, segundo Coutinho (2013), a ideia de institucionalizar a PHC, ocorreu na gestão do Prefeito Paulo Cezar Junqueira Hadich (PSB - Partido Socialista Brasileiro), e do vice-prefeito, Antonio Carlos Lima (PT - Partido dos Trabalhadores).

De acordo com a Professora F, a iniciativa de se institucionalizar a PHC no município partiu do professor José Claudinei Lombardi, que, ao assumir a secretaria municipal de educação, nesta gestão (2013-2016), propôs como condição, institucionalizar a PHC no município.

Prof Zezo (como é conhecido José Claudinei Lombardi) foi quem encabeçou, desde o início, a PHC como orientação a ser seguida na sua gestão à frente da secretaria de Educação. Buscou, para isso, além de fazer as possíveis articulações políticas necessárias para composição de alguns membros da equipe, como comissionados, com conhecimento teórico-prático sobre a PHC, como também promoveu uma ampla reestruturação administrativa à secretaria, buscando dar mais organicidade às ações. A diretoria pedagógica, da qual era diretora, pudemos contar com a valiosa colaboração, como já dito, de Ricardo Pereira (então pós-graduando na Unicamp) e Maria Cláudia Saccoma- 
ni (então pós-graduanda da UNESP) (RELATO DA PROFESSORA F. O primeiro parêntese é nosso).

De acordo com Lombardi (2015), ao assumir a Secretaria da Educação, teve como principal objetivo a elaboração e implementação de um projeto educacional fundamentado nos pressupostos teóricos da PHC. Inicialmente, procurou compreender as condições em que a educação estava estruturada, considerando vários aspectos, entre os quais, a estrutura física, administrativa e pessoal, para, a partir desta realidade, propor as transformações necessárias, por meio da elaboração de um projeto educacional para Limeira (LOMBARDI, 2015, p. 11).

Esse cenário educacional impôs inúmeros desafios. Segundo a Professora F, inicialmente, o principal desafio "foi o de promover mudanças nas diretrizes didático-pedagógicas da rede", adequando-as à pedagogia histórico-crítica. Para tanto, destaca duas ações importantes, visando, sobretudo, promover a superação das orientações fundamentadas no construtivismo:

[...] a primeira refere-se à formação dos profissionais da educação, sobretudo os docentes, buscando fundamentá-los teórica e praticamente para o desenvolvimento do trabalho educativo na perspectiva da PHC; de outro, e de forma articulada, o processo de elaboração de um currículo centrado nos saberes sistematizados, em substituição ao "rol de habilidades" no qual as escolas se embasavam (RELATO DA PROFESSORA F).

Além disso, de acordo com a entrevistada, o confronto com a concepção construtivista estava posto. No entanto, alguns aspectos pontuais, especialmente no que se refere à fundamentação didáticopedagógica, foram objeto de debates nos momentos de estudo dos fundamentos pedagógicos, especialmente porque havia uma perspectiva subjetivista decorrente do idealismo e do construtivismo ainda latentes.

Para Lombardi (2015), um dos principais desafios encontrados para institucionalizar a PHC como teoria pedagógica é trabalhar na contramão das tendências educacionais nacionalmente hegemônicas, assumidas segundo o viés ideológico do estado burguês e capitalista, o qual tem contribuído com a precarização constante "da infraestrutura, das condições de vida e de trabalho dos educadores e da qualidade do processo formativo", que gera a impossibilidade de realizar uma educação pública, 
gratuita, laica e de qualidade, fundamentada na cultura letrada, inviabilizando "aos alunos o domínio dos saberes historicamente produzidos pela humanidade", por meio da educação escolar.

Diante disso, para enfrentar os obstáculos decorrentes de uma organização educacional municipal alinhada às políticas nacionais de cunho neoliberal, o secretário de educação propôs à adoção de quatro grandes núcleos de ação, objetivando garantir o direito e o acesso à educação pública de qualidade para todos (LOMBARDI, 2015, p 9).

A materialização das ideias apresentadas por Lombardi (2015) ocorreu por meio de um programa que continha sete metas ${ }^{3}$ e ações correspondentes a serem desenvolvidas.

A partir da elaboração e socialização do programa educacional, das metas e ações, muitos trabalhos foram realizados com a intenção de institucionalizar a PHC. Esses estudos precederam a elaboração de um currículo municipal, que já era pensado antes do professor José Claudinei Lombardi assumir a Secretaria de Educação, em 2013. Porém, em parte, segundo a professora, isso obstaculizou a institucionalização da PHC.

\begin{abstract}
O processo de construção de um currículo foi um pouco mais difícil e, na minha leitura, pouco avançamos. Isso porque, desde a criação da rede pública municipal de ensino de Limeira, adotou-se as diretrizes da política educacional do estado de São Paulo, o que significa que há anos os profissionais da educação da rede recebiam orientações, formações, materiais didáticos com base nos fundamentos das pedagogias do aprender a aprender. A prática pedagógica dos trabalhadores da educação da rede estava toda ela fundamentada, com graus diferentes de consciência disso por parte dos profissionais, nessas teorias. Assim, toda a dinâmica do trabalho baseado nas habilidades e competências estava consolidado, mesmo que, não raro, questionamentos fossem levantados pelos próprios profissionais, de forma assistemática, da validade prática dessas orientações (RELATO DA PROFESSORA F).
\end{abstract}

No que se refere às motivações que levaram à institucionalização da PHC no município e os objetivos pretendidos, a professora destaca:

\footnotetext{
${ }^{3}$ Para melhor apropriação, consultar a bibliografia de Lombardi (2015).
} 
Sinteticamente, meu trabalho na secretaria foi motivado pela perspectiva de que é papel da educação, e aqui especificamente da educação escolar, socializar a riqueza cultural produzida histórica e coletivamente pela humanidade a cada indivíduo singular, para que se torne ser humano do seu tempo, capaz de, compreendendo a realidade histórico-social na qual vive, possa identificar os problemas sociais a serem superados no sentido da construção de uma outra sociedade, em que sejamos socialmente iguais, plenamente humanos (RELATO DA PROFESSORA F).

De acordo com Coutinho (2013), ao se referir à institucionalização da PHC em Limeira, afirma que os profissionais que trabalham na condução das redes de ensino precisam se preocupar com as condições concretas em que o ensino e a aprendizagem acontecem, oportunizando circunstâncias favoráveis para o desenvolvimento pessoal e social (COUTINHO, 2013, p. 183).

Nesse sentido, ao propor a institucionalização da PHC, o gestor e sua equipe pedagógica, controlam determinadas condições que incidem sobre o trabalho educativo. Assim, por exemplo, pode reorganizar administrativamente a gestão dos recursos materiais, financeiros $\mathrm{e}$ humanos e dos processos que envolvem o trabalho pedagógico (LOMBARDI, 2015), que facilitam a implementação da PHC.

De acordo com a Professora F, os principais desafios enfrentados na institucionalização da PHC em Limeira estão relacionados tanto à prática pedagógica como ao domínio da teoria e sua articulação com a gestão educacional.

Há um conjunto de desafios práticos, bem como teóricos. Isso porque, estamos vivendo um processo de maior organicidade na política educacional, com grande poder de regulação e controle do trabalho educativo. Soma-se a isso, que não podemos nos iludir em relação ao Estado Moderno que está a serviço dos interesses da acumulação de capital, o fazendo de diferentes formas. Qualquer outra orientação que se queira dar, confronta-se com esses limites estruturais, concretos, que atuam fortemente na limitação das nossas decisões e ações (RELATO DA PROFESSORA F). 
No entanto, diante dos limites concretos que incidem sobre o desenvolvimento de uma prática pedagógica orientada pela PHC, a professora adverte que é necessário elaborar novos estudos e novas pesquisas para avançar em vários aspectos, tais como: o domínio dos fundamentos, o currículo, as questões didático-pedagógicas, a organização dos conteúdos escolares e a gestão escolar.

Segundo a docente, o desenvolvimento de pesquisas pode indicar "pistas que nos permitam atuar de forma mais assertiva", para a institucionalização da PHC e transformar o trabalho educativo.

Porém, ressalta que não há fórmula para conduzir um processo de institucionalização da PHC, pois, cada realidade impõe os desafios que lhe são próprios, muito embora existam aqueles comuns a serem enfrentados em todos os locais.

\begin{abstract}
Ouso dizer, e só ouso, que por vezes, na ânsia de promover mudanças, esquecemo-nos de um princípio fundamental da PHC: o ponto de partida é a prática social, precisamos conhecer, minimamente, essa prática social, ter uma visão, ainda que precária, dessa prática social. Precisamos analisar os condicionantes concretos da situação e dos sujeitos reais no/com os quais iremos atuar. É a partir e nesta concretude, nessa realidade, com essas pessoas reais, que/com quem vamos trabalhar (RELATO DA PROFESSORA F).
\end{abstract}

Diante do exposto, percebe-se que o trabalho realizado para institucionalizar a PHC em Limeira procurou intervir em vários segmentos e atender uma vasta gama de demandas relacionadas à educação. Em seu conjunto, configuram um programa de objetivos, metas e ações que a secretaria de Educação e os docentes lançaram mão com o objetivo de institucionalizar a nova proposta pedagógica e educacional, calcada na PHC.

\title{
Conclusão
}

Como se pode perceber, a institucionalização da Pedagogia Histórico-Crítica se constitui num imenso desafio para as redes municipais de ensino. Apesar de limitadas, as experiências de Itaipulândia, Cascavel, Bauru e Limeira, realizadas em condições diversas, possibilitam extrair algumas conclusões, dentre elas, que não há uma forma única de promovê- 
la. Ao invés disso, dependem do contexto e das possibilidades de cada momento, em cada local.

Além disso, permitem depreender que, de forma mais ou menos direta, todas têm como referência a institucionalização do Currículo Básico para a Escola Pública do Paraná, em 1990. Consequentemente, as experiências de institucionalização da PHC realizadas pelas secretarias municipais de educação, também acabaram direcionando suas preocupações principalmente para a questão curricular.

Outro fator que contribuiu para isso, foram as diretrizes pedagógicas impostas pelo governo federal na forma de PCNs (Parâmetros Curriculares Nacionais), contudo, na contramão da PHC, pois, ao invés de valorizar os conhecimentos científicos, artísticos e filosóficos, eles esvaziaram seus conteúdos e descaracterizaram a função da escola de "produzir, direta e intencionalmente, em cada indivíduo singular, a humanidade que é produzida histórica e coletivamente pelo conjunto dos homens" (SAVIANI,2013a, p.13). No caso de Cascavel e Bauru, a institucionalização da PHC ficou mais restrita ao campo curricular, enquanto Itaipulândia e Limeira, simultaneamente, procuraram articular a nova proposta pedagógica à melhoria das condições de trabalho.

Seja de uma forma ou de outra, as experiências demonstram que a institucionalização da $\mathrm{PHC}$ não se resume à sua adoção pelos entes federativos. Ao contrário, constituem-se em longos processos, exigindo persistência, continuidade e determinação. De qualquer modo, revelam que é possível sim se instituir a pedagogia histórico-crítica e transformá-la no referencial teórico-metodológico para se implementar uma proposta pedagógica diferente das pedagogias hegemônicas existentes na atualidade.

\section{Referências}

BACZINSKI, Alexandra Vanessa de Moura. A implantação oficial da Pedagogia Histórico-Crítica na rede pública do estado do Paraná (1983 1994): legitimação, resistência e contradições. Campinas, SP: Autores Associados, 2011.

BALZAN, C. S. Os desafios da implantação e implementação da Pedagogia Histórico-Crítica nos anos iniciais do Ensino Fundamental em Itaipulândia

- Paraná. Cascavel, Unioeste, 2014. Dissertação de Mestrado. 
COUTINHO, L. C. Apontamentos sobre o processo de (Re)estruturação do sistema de educação municipal de Limeira-SP. Germinal: Marxismo e Educação em Debate, Salvador, v. 5, n. 2, p. 175-189, dez. 2013.

DUARTE, N. Vigotski e o "aprender a aprender" crítica às apropriações neoliberais e pós-modernas da teoria vigotskiana. Autores Associados, Campinas SP, 2004.

GASPARIN, J. L. Pedagogia Histórico-Crítica: teoria sem prática? Onde está o critério de verdade? Germinal: Marxismo e Educação em Debate. v. 5, n. 2, p. 89-96, dez. Salvador, 2013.

\section{LOMBARDI, J.C. Pedagogia Histórico-Crítica: desafios para sua}

implementação. Palestra realizada no dia 08 de julho de 2015, no

"Congresso Pedagogia Histórico Crítica: educação e desenvolvimento humano", realizado na Unesp, Campus de Bauru, ocorrido entre os dias 06 a 08 de julho de 2015.

MALANCHEN, Julia; ANJOS, Ricardo Eleutério dos. O papel do currículo escolar no desenvolvimento humano: contribuições da Pedagogia HistóricoCrítica e da psicologia histórico-cultural. Germinal: Marxismo e Educação em Debate, Salvador, v. 5, n. 2, p. 118-129, dez. 2013.

MARX, K. O Capital: crítica da economia política: Livro I: O processo de produção do capital. São Paulo: Boitempo, 2013.

ORSO, P. J; GONÇALVES, S. R; M, V. M. Educação, Estado e contradições sociais. 1. ed. São Paulo: Outras Expressões, 2011.

ORSO, P. \& TONIDANDEL. S. A Pedagogia Histórico-Crítica e o Currículo Básico para a Escola Pública do Paraná - 1990: do mito à realidade. Organização ORSO, P. J. [et al.]. Pedagogia histórico-crítica, a educação brasileira e os desafios de sua institucionalização. Curitiba, PR: CVR, 2014.

ORSO, P. Os desafios do conhecimento e o método da pesquisa científica. ETD - Educação Temática Digital, Campinas, v.5, n.1, p.25-39, dez. 2003 ISSN: 15172539. Campinas/SP, 2003.

SAVIANI, Dermeval. As concepções pedagógicas na história da educação brasileira. Campinas. SP. 2005. 
SAVIANI, Dermeval. Educação socialista, Pedagogia Histórico-Crítica e os desafios da sociedade de classe. In: LOMBARDI, J. C.; SAVIANI, D. Marxismo e educação: debates contemporâneos. 2 ed. Campinas, SP: Autores Associados, 2008.

SAVIANI, Dermeval. Escola e democracia. 42. ed. Campinas, SP: Autores Associados, 2012.

SAVIANI, Dermeval. Pedagogia Histórico-Crítica: Primeiras aproximações. 11 ed. rev. Campinas, SP: Autores Associados, 2013a.

SAVIANI, Dermeval. História das ideias pedagógicas no Brasil. 4. ed. Campinas, SP: Autores Associados, 2013b.

SAVIANI, D. DUARTE, N. Pedagogia Histórico-Crítica e luta de classes da educação escolar. Campinas, SP: Autores Associados, 2012.

SILVA, J. C. et al. Pedagogia Histórico-Crítica, a educação brasileira e os desafios de sua institucionalização. 1. Ed. Curitiba, PR: CRV, 2014. 